\title{
Unleashing Entrepreneurs or Controlling Unruly Providers? The Formalisation of Small-scale Water Providers in Greater Maputo, Mozambique
}

\author{
Rhodante Ahlers, Valeria Perez Güida, Maria Rusca \& Klaas Schwartz
}

To cite this article: Rhodante Ahlers , Valeria Perez Güida , Maria Rusca \& Klaas Schwartz (2013) Unleashing Entrepreneurs or Controlling Unruly Providers? The Formalisation of Small-scale Water Providers in Greater Maputo, Mozambique, The Journal of Development Studies, 49:4, 470-482, DOI: $10.1080 / 00220388.2012 .713467$

To link to this article: https://doi.org/10.1080/00220388.2012.713467

\section{曲 Published online: 26 Nov 2012.}

\section{Submit your article to this journal $\llbracket$}

Lll Article views: 440

Citing articles: 11 View citing articles $\square$ 


\title{
Unleashing Entrepreneurs or Controlling Unruly Providers? The Formalisation of Small-scale Water Providers in Greater Maputo, Mozambique
}

\author{
RHODANTE AHLERS, VALERIA PEREZ GÜIDA, MARIA RUSCA \& \\ KLAAS SCHWARTZ \\ UNESCO-IHE Institute for Water Education, Delft, Netherlands
}

Final version received May 2012

\begin{abstract}
The existing legal and policy framework regulating water service provision in Greater Maputo, Mozambique appears fixated on the official service areas. In doing so it inadequately addresses the geographically varied service provision modalities which characterise the city. We argue that the predominant legal and policy framework does little to support development of improved services in areas unserved by the formal utility. Although ad hoc measures recognising small-scale providers as a temporary alternative to service provision by a formal utility have been implemented, these measures appear designed to increase control over these providers rather than support the service delivery capacity of small-scale providers.
\end{abstract}

\section{Introduction}

Confronted with projections of urban growth in the coming decades, multinational and bilateral developing agencies have been forced to give increasing attention to rapidly growing cities in the developing world (Hansen and Vaa, 2004). In the approach adopted by these organisations, considerable emphasis is placed on 'formalisation' of the informal economy (Schaub-Jones, 2008). The approach to formalisation most often propagated by both international lending agencies (World Bank, 2009a; ADB, 2007, 2008) and academics (Solo, 1999; Njiru, 2004; Schaub-Jones, 2008) can best be described as what Rakowski (1994) terms a 'legalist approach' to formalisation. The principal idea of the legalist approach is that the existing capitalist system works, but players in the informal economy hold the resources to partake in this capitalist system in 'defective forms' (de Soto, 2000: 5). Central to this argument is the notion that without formally recognised property rights, assets are unable to flow freely through the market (Portes and Schauffler, 1993). Informal enterprises in this perspective are perceived as economic assets that should be 'revived by the official legal system and turned into liquid capital so people can gain access to formal credit, invest in their [... ] businesses, and thus reinvigorate the economy as a whole' (Fernandes, 2002: 2; see also Woodruff, 2001). By formalising these 'informal' enterprises, a large pool of entrepreneurs will be unleashed. 
A key component of the legalist approach is the issue of legal titles. Once entrepreneurs obtain legal titles they will be able to participate in the formal market. Additional policy prescriptions deriving from the legalist approach are aimed at easing capitalist exchange within the boundaries of the state. These policy prescriptions include de-regulation, simplification of administrative procedures, privatisation and the elimination of protectionism. The legalist approach and the associated policy prescriptions have been part and parcel of the neo-liberal turn in policy-making since the 1980s, jumpstarted by the structural adjustment prescriptions of the World Bank and the International Monetary Fund (IMF) (Bromley, 1990; Meagher, 1995).

When the failure of full-fledged privatisation in the water sector became clear, de Soto's (2003) call to reconstitute small-scale informal sector enterprises as full-fledged private sector actors by the provision of property rights resonated strongly within the water sector. The World Bank consequently introduced 'formalisation' as a policy objective so as to bring these so-called informal enterprises into the realm of a market more controlled by the state through policies and regulations (World Bank, 2003, 2004).

In this article we focus on small-scale independent water providers (SSIPs) in Maputo Mozambique, and examine both the assumptions behind this policy directive of formalisation, as well as the expected outcomes. As with regards to the assumptions, we identify two main points of concern. First, policies promoting the formalisation of urban service delivery are typically structured by a very narrow understanding of the diversity of private sector actors involved, not taking the diversity into account and that their primary interest may not be maximising profit. Second, the complexity of informal service delivery is greatly underestimated as one that can be easily moulded into a formal regulatory framework. The underlying assumption is that informality takes place in an institutional void that can simply be filled with rules and regulation. In reality, these settlements have developed informal institutional arrangements that have come about as a result of recurrent daily practices, interactions and transactions of its dwellers (Assaad, 1996; Kudva, 2009; Guha-Khasnobis et al., 2006).

Regarding the projected outcomes that the policy of formalisation is argued to achieve, little empirical precedence supports this claim. According to Guha-Khasnobis et al. (2006: 9) 'the experiences indicate that no simple rule exists that increasing or decreasing formalisation necessarily improves or worsens the well being of the poor or welfare of society at large.' Consequently, this article asks two questions: (1) will bringing informal entrepreneurs into the regulatory system of the formal economy actually unleash them?; and (2) will this improve service delivery for consumers?

Underlying these questions is the well established awareness of how the formal economy is dependent on informality and that capitalist relations of production fare well when some of these relations subvert regulation (Kudva, 2009). The formal and informal sector are intimately linked with the informal sustaining the formal. Their distinctive features and spatial manifestation are a result of social historical processes. One could argue that formalising the informal sector may stifle the flexibility and dynamics that informality allows for. The informal sector provides cheap services that the formal economy depends on because they fall out of state regulation as well as trade union organising. On the other hand, the costs of this arrangement may be quite high, with labour exploitation, clientalism and poverty on the one hand, and environmental pollution on the other. This is also true in the case of informal water service provision. There is very little control of water quality, great differentiation of price and little monitoring and certainly no prevention of resource depletion or degradation. Our concern in this article is to examine whether the formalisation of informal water service providers is appropriate to improve water provision.

We examine how 'formalisation' policies unfold in practice by examining the case of smallscale informal water providers in Greater Maputo, Mozambique. The fieldwork for this study was carried out in 2009. Semi-structured interviews were held with 13 SSIPs of different sizes, directors of the two SSIP associations, representatives of the water utility supplying water to Greater Maputo, public entities involved in the water services sector, representatives of international development agencies and non-governmental organisations (NGOs), private 
independent consultants and customers of SSIPs. The SSIPs interviewed vary from a small provider serving 24 connections to a relatively large provider servicing almost 2000 connections.

Before exploring the case of Maputo, we explain the increased interest in the water sector towards private sector participation and the role of the SSIPs therein. The next section highlights the historic and social processes driving the uneven spatial development in Maputo and explains how SSIPs have stepped in to service large areas of the city where the formal utility has remained absent. After having discussed the formalisation policy and how it is implemented, we show how the involved government agencies and the SSIPs perceive this process, and who will reap the benefits.

\section{Inserting the Private Sector into Water Provision}

At the beginning of the Drinking Water Decade (1981-1990) the lack of adequate water and sanitation services in developing countries was predominantly viewed as a 'hardware' problem. Resource and infrastructure shortages were seen as the main impediments to providing services to all. With the neo-liberal turn during the 1980s, the problem construction underlying inadequate water services changed. Increasingly, 'institutions' were prioritised as the prime obstacle to improvement of services. This growing emphasis on institutions was reflected at large international conferences in New Delhi (1990) and Dublin (1992), ${ }^{1}$ where institutional reforms were advocated. A typical argument underpinning this shift is provided by two frequently cited economists, Spiller and Savedoff (1999: 2), who formulate the causes of poor performance of the water services sector as follows:

The nature of the sector, coupled with a nation's political institutions, [...] together create incentives for government-owners of public utilities to behave opportunistically, for the service providers to operate inefficiently, and for the consumers to withhold support to the sector. As such, the water services sector under these circumstances has a tendency toward a low-level equilibrium from which it is difficult to escape.

The quote shows that the challenge of providing water services is largely reduced to an economic transaction. Because the actors in the sector (providers, politicians, consumers) fail to behave as rational market players, there must be something wrong with the sector institutionally. Addressing these 'institutional' obstacles was done in the context and language of the increasingly neo-liberal global policy context. In water services, this essentially translated into privatisation and commercialisation ${ }^{2}$ of the sector. 'Private institutions' (Bakker, 2002), 'market organised production' (Swyngedouw, 2005) and 'private sector ethos' (Smith, 2004) became the cornerstone of reforms in the water services sector during the 'water privatization decade' (Franceys, 2008). Central drivers of reform were cost recovery, competition and consumer choice.

In order to enable these reforms many countries implemented new water policies and adopted new water laws. In sub-Saharan Africa, countries such as Senegal (1995), Uganda (1998-2001), Mozambique (1999), Namibia (2000), Zambia (2001), Kenya (2002) and Tanzania (2002) reformed their water service sectors. A shared theme of these reforms is that they envisaged a single (private) utility providing universal and standardised services and operating according to private sector and market institutions. As such, the reforms initiated in the 1990s maintained a strong adherence to the 'modern infrastructural ideal' (Graham and Marvin, 2001) or the 'integrated urban ideal' (Gandy, 2004). Developed in Western cities in the first part of the twentieth century, the modern infrastructural ideal envisages a networked city with infrastructure monopolies providing standardised and universal services (Graham, 2000; Joshi and Moore, 2004).

Contrasting with these reforms and the 'integrated urban ideal', however, are the actual service provision realities in the towns and cities of these middle and low-income countries. Bakker characterises these as archipelagos with service provision consisting of 'spatially separated but 
linked "islands" of networked supply in the urban fabric' (2003: 337). The 'islands' in Bakker's analogy are serviced by formal utilities, whilst the unserved areas surrounding these 'islands' are serviced by 'informal' service providers or small-scale independent providers (SSIPs). These SSIPs have filled a service delivery gap left by the formal utility's inability or unwillingness to expand services of adequate quality to the growing towns and cities (Batley, 2006: 243). Despite filling this gap, SSIPs were largely ignored by international lending agencies, donors and (national) governments as they did not match with the integrated urban ideal (Collignon and Vézina, 2000).

\subsection{The Reappraisal of SSIPS}

In recent years, small-scale independent water providers have been increasingly hailed as an acceptable complement to the provision of services by a formal public or private utility. Two reasons appear to underlie this shift in thinking about SSIPs. First of all, the challenge of achieving the Millennium Development Goal (MDG) targets for water supply and sanitation has led to a reconsideration of existing modes of service delivery. The MDG targets for water supply services state that the population without access to adequate water services should be halved by 2015. Although progress is reported on these targets, especially access to adequate water services in sub-Saharan Africa is lacking. Between 1990 and 2006 the percentage of people with access to adequate water services increased from 49 per cent to 58 per cent, which represents an increase of only 9 per cent in 16 years. Considering that almost 75 per cent coverage should be achieved by 2015, considerable (additional) efforts are needed to achieve the MDGs (WHO/UNICEF, 2008). By formalising SSIPs and, as such, bringing them into the formal service provision system, considerable gains can be made in terms of achieving the MDGs (see Eales, 2008). Second, following the disappointing results of the 'water privatisation decade' which ended in 2003, proponents of private sector involvement have been searching for new private sector champions in the water services sector. One of the ways in which the role of the private sector is again receiving attention is through an increased focus on small-scale independent providers. In effect, the promise attributed to large multinational private sector at the start of the 'water privatisation decade' appears to have been substituted for that of small-scale private sector. The entrepreneurial spirit of SSIPs is increasingly accentuated by describing them as 'small-scale entrepreneurs' (Eales, 2008), 'independent water entrepreneurs' (Solo, 2003) and 'local entrepreneurs' (Conan, 2003) instead of 'informal providers'.

The promise of SSIPs is argued on several points and punctuated by the neo-liberal emphasis on efficiency through cost recovery and competition. First of all, the SSIPs provide services where the formal utility does not. Specifically, the SSIPs cater their services for the inhabitants of fast growing unplanned peri-urban settlements (Snell, 1998; Kjellén and McGrahanan, 2006). Second, the SSIPs are argued to operate on the basis of full cost recovery and therefore would require no government subsidies (Solo, 1999). This, in turn, provides the SSIPs with a strong incentive to reduce costs, and thus reduce wastage such as unaccounted for water (Solo, 1999). A third argument concerns the flexibility and innovativeness of the SSIPs (Solo, 1999; Plummer, 2002; Njiru, 2004; Kjellén and McGranahan, 2006; Schaub-Jones, 2008). Hence, SSIPs are considered to be highly demand-responsive (Solo, 1999; Schaub-Jones, 2008) or as Njiru (2004: 446) argues, SSIPs are 'customer focused, providing differentiated services and meeting the various needs and demands of customers'. A final argument is that SSIPs are willing and able to make significant investments in a service provision system (Schaub-Jones, 2008).

Most of these authors also highlight the constraints which inhibit the performance of SSIPs. These constraints include the frequent opposition of formal utilities to work with the SSIPs (Njiru, 2004), the lack of official recognition of SSIPs (Sansom, 2006), difficulties of regulating the SSIPs (Sansom, 2006), limited access to water sources and inadequate financial resources (Conan and Paniagua, 2003). In order to mitigate these constraints, formalisation of SSIPs is increasingly being propagated (Njiru, 2004; Samson, 2006; ADB, 2008; Schaub-Jones, 2008; 
World Bank, 2009a, 2009b). The underlying idea is that formalising SSIPs will not only benefit these providers themselves, but that ultimately the benefits of formalisation (in terms of lower costs and better services) will be 'passed on to consumers' (World Bank, 2009a: 70).

\section{The Multiple Service Provision Modalities in Greater Maputo}

The current service provision realities in Greater Maputo reflect the city's historic development. Characteristic of Greater Maputo's growth is the coexistence of unplanned urban expansion alongside limited formal urban development enjoyed by a small urban elite of changing composition. Under the Portuguese colonial administration, urban policies favoured the colonial residents as well as the indigenous elite that cooperated with the colonial administration. Colonial and indigenous elites generally occupied the formal city centre, known as the "cement city'. The remaining and majority of the indigenous population was consigned to inhabiting the outlying urban areas resulting in a spatial distribution of the population 'on distinctly racial lines, with the majority of African residents living outside the planned urban area' (Jenkins, 2000: 208).

Following independence in 1975 the Frelimo government initiated a programme of nationalisation. Although the urban policies of Frelimo signalled a break from the policies of the colonial administration, the main beneficiaries of these policies were limited to party members and supporters (Pitcher, 2006; Paasche and Sidaway, 2010). Alongside the formal reallocation of land and housing to new governing elites, a surge of unplanned urban growth characterised the peripheral urban areas. This 'informal' urban development manifested itself beyond the reach of formal governance and was regulated through 'a myriad of highly localised and dispersed governance rules that developed beyond the purview of the state' (Lindell, 2009: 1882; see also Jenkins and Wilkinson, 2002).

A devastating civil war in the 1980s and a faltering economy pushed the Mozambican government to the World Bank and IMF, which prescribed a structural adjustment programme that was implemented from 1987 onwards. The subsequent neo-liberal reforms ${ }^{3}$ resulted in significant hardship for a large part of the (urban) population and provided a further impetus for informalisation of the urban economy (Lindell, 2008).

The current service provision system in Greater Maputo reflects these socio-historic processes and their spatial manifestations. Broadly, the urban space can be divided into three different service areas (Conselho de Regulação do Abastecimento de Água - CRA, 2007). The first service category concerns the 'cement city'. In this area, where provision is to be supplied through in-house connections, service delivery has been delegated to the then contracted private company Aguas de Moçambique (AdeM), which was replaced by Aguas da Região de Maputo in 2011. The second category concerns a 'mixed' area as it officially falls within the service area of AdeM, but is only partly served by the utility. Where AdeM is unable to provide services, SSIPs have filled the service provision gap. In some of these areas the formal network has been expanded in recent years and now overlaps with networks of SSIPs. Finally, a third category concerns areas of Greater Maputo which lie outside the official service area of AdeM. This area, characterised by a rapidly growing peri-urban population, is served mostly by SSIPs (CRA, 2007). This third category mainly consists of peri-urban neighbourhoods furthest removed from the 'cement city'.

\subsection{Small-scale Providers in Maputo}

In Greater Maputo an estimated 350-450 small-scale independent providers (SSIPs) service 37,000-44,000 household connections and 320 standpipes (SAL, 2006). The SSIPs are progressively capturing a larger share of the water supply market in Greater Maputo. The SSIP market was estimated in 2006 at approximately US\$6.5 million, which represents about 46 per cent of the peri-urban market (Blanc, 2008). 


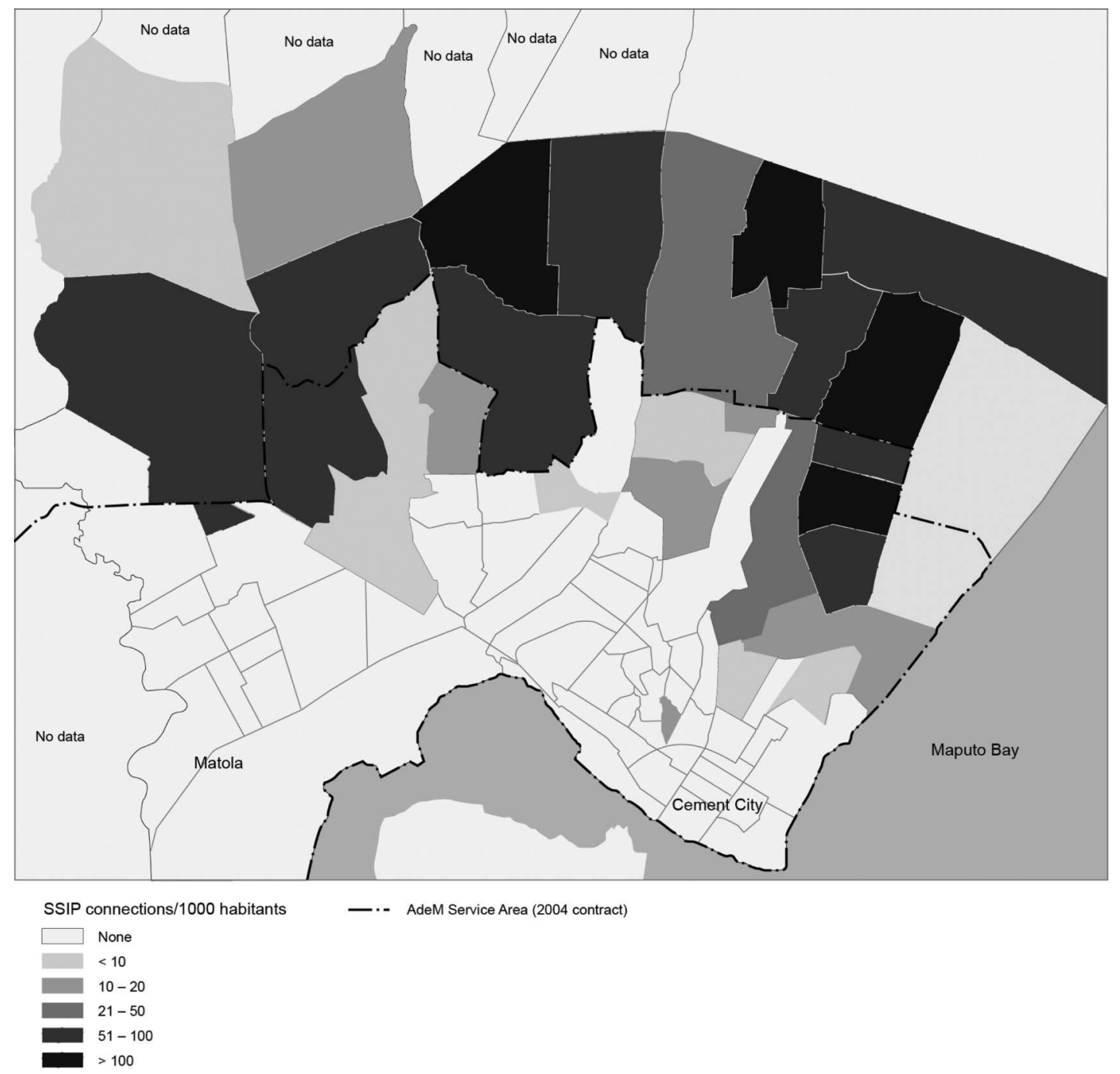

Figure 1. Prevalence of SSIPs in Greater Maputo. Source: Authors based on information from FIPAG (2009).

The SSIPs in Greater Maputo are tremendously diverse. They show a variety of organisational forms, differ in the scale of their operations, adhere to different business approaches, and provide services through different types of infrastructure. An SSIP can be a single person selling water from a borehole to neighbouring clients or a multi-staffed business that serves thousands of households through network systems. Some SSIPs have been initiated inadvertently rather than by design and the activity of providing water generates a supplementary source of income for the household. Others have carefully planned the business and providing water services forms the main income for the owners of the SSIP. There is also a distinction in the infrastructure used for delivering services; this can be either a spaghetti network or a structured network. ${ }^{4}$

The level of service ${ }^{5}$ delivered by the SSIPs also shows significant differences between the SSIPs. Some SSIPs are able to provide a better service than the formal utility in terms of service continuity and water pressure. In certain areas, they are known to produce relatively poor and expensive services (Blanc, 2008; Boyer, 2006; Hydroconseil, 2008; Matsinhe et al., 2008). In terms of water quality, none of the interviewed SSIPs treats the water before distribution. The quality 
of the water supplied therefore relies mainly on the quality of the groundwater abstracted. The water tariff charged by the SSIPs varies between $20 \mathrm{MZN} / \mathrm{m}^{3}$ to $40 \mathrm{MZN} / \mathrm{m}^{3}$. ${ }^{6}$ In comparison with the average price charged by AdeM, the tariffs of the SSIPs in our sample were, on average, 38 per cent higher.

In terms of cost recovery and competition, the SSIPS suffer similar monopoly-like characteristics as the 'formal' water supply sector due to the combination of sunk costs (infrastructure to connect the household and pump the water) and economies of density (an extra customer linking onto the network does not increase costs tremendously while a customer outside the network does). The SSIPs transfer the cost of the infrastructure onto the consumer through a connection fee, separate from the water bill. The connection fee varies substantially among the SSIPs, ranging from US\$40-100 excluding materials, to \$US48-120 including them. Interestingly, in our sample the smaller scale SSIPs have both the highest and lowest water tariff and the highest and lowest connection fee. Once a provider has captured the market, the customer is locked in due to the infrastructure used and the high connection fee, and has little (if at all) room to switch providers. Furthermore, cartel-forming by the larger SSIPs essentially regulates the SSIP sector. These SSIP associations regulate the price to be charged, the entrance of new providers to particular areas, and the extension of infrastructure into existing or newly tobe-developed service areas. What is hailed as 'free entry' to the market, or 'healthy' competition, is in reality a power play determined by economically unequal actors, locationally determined social relations, and historic uneven development.

In sum, the situation of the SSIPs of Greater Maputo shows us that that they are tremendously diverse and competition between them is limited. Furthermore, customers tend to be captive, as once they have paid for the substantial connection fee and the necessary materials to access water close to their home, they are reluctant to shift.

\section{The Mozambican Formalisation Policy}

The National Water Policy (7/95) of 1995 forms the cornerstone of the legal and policy framework regulating the water services sector in Mozambique. The National Water Policy (NWP) calls for private participation in the provision of water and sanitation services in the form of 'contracts, concessions or direct investment' (art. 2, i). The NWP also seeks enhanced autonomy of the water service provider and envisions the involvement of the private sector as an opportunity to achieve this goal. It also acknowledges the presence of an informal private sector: 'The informal [private] sector supplies water to the population that is not connected at the existing network, for instance in rural and peri-urban areas. A better utilization of this already existing capacity could improve levels and quality of service delivery through formal agreements' (National Water Policy, art 2, i, 1995). However, the same document also highlights that 'the most vulnerable sector of the population, mostly the ones living in peri-urban areas, pay much more [for water] than other sectors that have access to better services' (art. 3). The NWP fails to provide clear indications of the role that these providers could assume and how these should be integrated into the formal system.

The application of the NWP began in 1998, with the introduction of the Delegated Management Framework (DMF). Delegated management is defined as a coordinated set of organizations and legal mechanisms that allow the participation of private entities in the management of public water services' (Decree 72/98, art. 1c). Under the DMF operation and management of public water systems are delegated or can be delegated to private operators and asset management is separated from the operations of urban supply systems. A new entity was created for asset management called the Fundo de Investimento e Património do Abastecimento de Água (FIPAG). The DMF also created a regulator called the Conselho de Regulaça do Abastecimento de Água (CRA) whose responsibilities include the regulation of water services and tariffs, protection of consumers and mediation and arbitration between the contracting entity and the operator. The introduction of the DMF marks a significant shift from the government as 
provider of services to one of enabling and regulating service provision by a private operator (Zandamela, 2001; Matsinhe et al., 2008). Given its emphasis on service provision by a single provider and ownership of the infrastructure by the asset-holding company FIPAG, however, the framework provides little room for SSIPs.

With regard to the SSIPs, the issuance of licences forms the basis for formalisation. These licences are, however, not specifically designed for the purpose of formalising SSIPs, nor is there an explicit policy framework within which these licences are embedded. Rather 'formalisation' is pursued by applying existing and rather general administrative instruments.

For SSIPs operating outside the service area of AdeM, formalisation essentially encompasses the acquisition of four separate licenses: (1) for water distribution issued by FIPAG; (2) for groundwater abstraction issued by ARA-Sul; ${ }^{7}$ (3) to occupy municipal land issued by the municipalities; (4) a commercial license also issued by the municipalities. ${ }^{8}$ In case the SSIPs operate in the 'mixed' areas, an agreement (or sub-concession) with AdeM would have to be entered into in addition to these four licenses. This agreement would entail that AdeM sells bulk water to the SSIPs. The SSIP then distributes the water using their infrastructure. The exact terms for these agreements are still under discussion between AdeM and the SSIP associations. ${ }^{9}$ Apart from the one-year license issued by FIPAG, the other licenses are already existing standard licenses. The SSIPs in this respect are simply brought into the regulatory system of the state.

The policy of licensing SSIPs by FIPAG was first launched in 2007. The driver for this policy was the expansion of the formal network to the eastern part of Maputo. ${ }^{10}$ In this area, in which services were provided by SSIPs, the formal network overlapped with those of the SSIPs. As explained by an employee of FIPAG, '... at that moment we realised that it was necessary to license all the SSIP including those outside the lease area, in order to have the information where they are and use that information to plan the investments'. ${ }^{11}$ For SSIPs to qualify for the oneyear license they have to submit a registration form to FIPAG containing personal information, level of service provided, tariffs, infrastructure and other administrative documentation. In addition, the quality of water provided by the SSIP needs to be analysed by the Ministry of Health. Finally, a technical visit from FIPAG is required to confirm the information.

Both FIPAG and ARA-Sul foresee that the requirements for licensing will become more rigorous in the near future. For example, the FIPAG license currently poses no constraints on the tariffs charged or the service area of the SSIP. FIPAG expects that also these aspects will be incorporated in the license in due course. The groundwater abstraction license currently only contains information about the location of the borehole, amount of water abstracted and purpose of water use. In time, this license will likely also charge the license holder for water abstracted. $^{12}$

The perspectives on formalisation of FIPAG and ARA-Sul suggest that formalisation, first and foremost, is targeted at controlling SSIPs with the ultimate aim of integrating the SSIPs into the existing legal framework for water provision services (once the 'formal' network is extended to the entire city). ${ }^{13}$ According to a representative of ARA-Sul, the organisation responsible for groundwater management, formalisation of SSIPs allows the organisation to gather information on groundwater abstraction and comply with their mandate of managing water resources by regulating the location of the boreholes and the amounts of water abstracted. ${ }^{14}$ FIPAG believes that a register of SSIPs would facilitate their administrative and planning procedures. This would allow FIPAG to identify where networks are missing and should be expanded. ${ }^{15}$ Such a register would also insert water provision by SSIPs in the official counting of service coverage, useful in the achievement of the MDG for water supply. ${ }^{16}$

The focus on licensing is not accompanied by any attention on service improvement. No financial support in the form of soft loans or subsidies is given to the participating SSIPs, nor is much done to support the existing SSIP associations. No training is provided for SSIPS to enhance water quality standards or facilitate infrastructure maintenance. What the licensing process furthermore highlights is that the formal water organisations (FIPAG, CRA and AdeM) 
consider SSIPs as a provisional solution that will be replaced by a permanent one in due time. An exception to this is a pilot project with three operators as part of a European Union funded project called the Maputo Water Supply Project (Chaponniere and Collignon, 2011). Through the provision of a publically funded primary network leased to an SSIP, the three informal providers can access subsidies by increasing coverage. Part of this relationship with FIPAG would involve a five-year license and the possibility to access a subsidy per added connection for a period of two years. The resulting increase in coverage is tremendous and shows that the SSIP does not necessarily need to be replaced. Weaknesses of the project are identified as having high water losses in the system (Chaponniere and Collignon, 2011: 7). It is unclear from this project to what extent this has improved the quality of the service, in terms of water quality and continuity. Also, the project focussed on those SSIPs that have access to investment capital upfront, and subsidising the provider does not necessarily translate into improved access to the poor as the authors argue. Hence the support in this case is focused on the provision of the primary network, rather than on improvement of the service.

The provisional nature of SSIPs as a complementary service modality is illustrated in an unpublished FIPAG document, which states that '...during a transitory phase water supply should be provided by using alternative infrastructure... Once the funds are available it is obvious that there will be an expansion of the conventional network. .. ${ }^{17}$ The need for formal network expansion is argued on the basis that it avoids the overlapping of distribution networks, safeguards standards ${ }^{18}$ of service delivery, and ensures long-term availability of groundwater resources. ${ }^{19}$

The transitory nature of SSIPs as an accepted complementary service modality is further underscored by the fact that these providers are offered a license for only one year. Such a license can be revoked annually. Such a short duration hardly reflects the capital investment SSIPs make, nor does it provide the necessary security to access additional financial resources (through loans). Moreover, the costs for becoming 'formal' are considerable. Apart from license fees, the SSIP must also start to pay taxes (in case they were not doing so already) and in the future are likely to be charged for water abstraction.

In sum, formalisation is perceived by the agencies as a procedure to make informal providers more visible to them, to gain insight about their service area, and as transitory trajectory towards full incorporation of them. For the SSIPs, the licences will mean an increase in cost. Several of the SSIPs in our sample said the licences improve their status; they bring a level of recognition. For others the increased costs and visibility make them wary of the procedure, especially if more regulations follow in the future. Because the increased formalities do not come with any training so as to facilitate service delivery, there is very little incentive to embark on the process. One of the obstacles to service improvement more frequently mentioned by SSIPs is access to financial resources, which is not addressed through this licensing scheme. The larger SSIPs organised in the SSIP associations see more benefits. They find that their negotiating power may be sufficient to prevent incorporation into the main utility and for them formalisation may be a good business investment.

For the consumers, formalisation has little effect in the short run and no clear effect in the long run. If SSIPs operate on the basis of full cost recovery, these costs will then be passed on to their consumers, increasing the price of water for them. Given that they are captive customers this means that formalisation will bring increased costs to the consumer as the costs of formalisation will be passed on to the consumer. There is no provision in the policy for improving service delivery with respect to quality of continuity; hence the customer is unlikely to benefit from the policy.

\section{Conclusion}

In this article, we have examined how 'formalisation' policies unfold in practice, and to what extent the assumed character of the informal service provider and the expected outcome of 
formalisation holds true in the case of small-scale informal water providers in Greater Maputo, Mozambique. The SSIPS in our case show that they provide a valuable service where the formal utility does not reach. Stripped from the ideological suit they have been given - full cost recovery, flexible and innovative, high demand responsive, high investment in service - SSIPs in our case reveal diversity in the infrastructure they use to provide water, the number of connections they service, the size of the business and the level of professional organisation. Competition between the SSIPs is actually quite limited given the captive customers, locked in by infrastructure and high connection fees, and the strong-arm tactics of the large SSIPs organised in provider associations. Hence, SSIPs as small-scale informal private actors come in great variety and more often than not deviate from the ideal-type private-actor neo-liberal scholars and policy-makers suggest them to be.

Contrary to much of the literature deriving from international lending agencies, sector professionals and academics on formalisation, SSIPs are only perceived by the Mozambican water organisations as an acceptable complement to service provision if they comply with conditions that only the larger SSIPs can fulfil. This is clearly shown in the pilot project that provides access to a primary network and subsidies to increase coverage for a limited number of years. In this sense the SSIPs become subcontractors and the integrated urban ideal, with its emphasis on a single provider servicing the entire city with a universal standard of services as stipulated in the existing legal and policy framework, remains the guiding principle of service provision. As explained by an employee of the regulator (CRA) '... .under the actual situation there are several networks operated by different providers. Furthermore, these networks are not conventional. Nobody wants a city like that. . ${ }^{20}$ Although literature on formalisation of SSIPs emphasises entrepreneurship, the actual 'formalisation' policies appear to be more centred on allowing this only to flourish within strict boundaries, hence restraining this entrepreneurship rather than unleashing it. Without doubt, monitoring water quality, price and continuity is important for the consumer, while monitoring abstraction is adamant for the sustainability of water provision over time. But current activities of formalisation are primarily focused on the network, the licence and the coverage, very much in line with reaching the MDGs.

A formalisation policy geared towards expanding control over, rather than capacitating, the SSIP sector has a number of important consequences. First of all, given the diversity of SSIPs it is unlikely that formalisation will have a uniform impact on the different SSIPs. Most likely, formalisation will allow larger SSIPs, who are able to shoulder the cost of formalising and who are able to engage in negotiations with the formal water organisations, to secure their market position and provide opportunities for business expansion (particularly in areas outside AdeM's service area) as shown by Chaponniere and Collignon (2011). As a result, formalisation may also bring benefits to these providers (see also Fischer, 2007). For smaller SSIPs, on the other hand, becoming formal may be less appealing. With formalisation comes costs, such as license fees, taxes and expenses related to ensuring basic service standards. For the smaller SSIPs, already struggling to survive, these costs are considerable. Given the investments these smaller SSIPs have made in infrastructure, such as a borehole and a pump, they are unlikely to cease their service provision activities as this would essentially encompass writing off the investments. Rather than opt for a formal status, these SSIPs are likely to continue to operate informally or perhaps in a deeper form of informality.

Second, the existing formal legal and policy framework and the current formalisation policy do little to protect the interests of the consumers who are dependent on SSIPs. Much of the (legalist approach inspired) literature on formalisation on SSIPs argues that the benefits of the entrepreneurship of SSIPs will ultimately be the consumers (see Njiru, 2004; van Dijk, 2008; World Bank, 2009a), ${ }^{21}$ and that under the right conditions SSIPs will fully exploit the looming market opportunities. Formalisation, in that perspective, is predominantly viewed as an opportunity to mitigate the constraints facing SSIPs (Njiru, 2004; Sansom, 2006; Conan and Paniagua, 2003; Schaub-Jones, 2008). With the actual policy of formalisation being geared to bringing SSIPs into the fold of the formal network of provision, rather than focussing on 
capacitating them, the consumers are unlikely to benefit in the near future. In fact, it is more likely that costs associated with becoming formal are passed on to consumers instead of the 'benefits' of formalisation.

\section{Acknowledgements}

This research was funded by the Netherlands Ministry of Development Cooperation (DGIS) through the UNESCOIHE Partnership Research Fund. It was carried out in the framework of the Research Project 'Partnerships in the Water Supply and Sanitation Sector in Sub-Saharan Africa'.

\section{Notes}

1. Global Consultation on Safe Water and Sanitation for the 1990s in New Delhi and the International Conference on Water and the Environment in Dublin.

2. Privatisation can be defined as the 'organizational change in ownership (from public to private) and management (from near-complete public control of water-supply functions to the involvement of the private sector). Commercialization entails changes in water supply institutions, with the application of private sector institutions (e.g., markets,) and culture (e.g., efficiency, competition and economic equity advancement)' (Bakker, 2002: 768-769).

3. These included a devaluation of the currency, the reduction of state subsidies for various social services, restoration of markets, the elimination of price controls and privatisation (Pitcher, 1996).

4. A spaghetti network is one in which individual distribution lines connect the consumer with the source of potable water. Each consumer basically has an individual distribution pipe; while a structured network uses primary and secondary (and possibly tertiary) pipes to distribute the water, followed by individual connections to the customer premises.

5. Service level is defined in terms of continuity of service, water quality, water tariff and connection charges.

6. US\$0.74 per $\mathrm{m}^{3}$ to US $\$ 1.48$ per $\mathrm{m}^{3}$.

7. ARA-Sul is responsible for groundwater management.

8. SI/FA1.

9. The reappraisal of the role of SSIPs came together with the formation of two SSIP associations, the Associaça do Fornecedores Privados de Água Subterrânea (AMATI) and the Associação dos Fornecedores de Água de Moçambique (AFORAMO), created in 2004 and 2006 respectively. Both associations are the main intermediaries between individual SSIPs and the authorities in the process towards the formalisation of SSIPs.

10. In particular, the construction of the Laulane Distribution Center accelerated the development and implementation of the 'formalisation' policy.

11. SI/FA1.

12. SI/FA5.

13. SI/MA3, SI/MA4, SI/MP3, SI/FM4, SI/FA1.

14. ARA-Sul.

15. SI/FA1, SI/FA6.

16. FIPAG.

17. SI/FA1.

18. SI/FA4, SI/FA1.

19. SI/FA4, SI/FA5.

20. SI/FA4.

21. The consumer as beneficiary of a legalist approach to formalisation is based on the assumption that competition in the small-scale sector exists. Our research in Mozambique questions this underlying assumption (see Perez Guida, 2009).

\section{References}

Asian Development Bank (ADB) (2007) Water for Slums: Small Piped Water Networks Deliver in the Interim (Manila: Asian Development Bank).

Asian Development Bank (ADB) (2008) Delivering Piped Water on a Small Scale: Result of ADB's Water Supply Service Market Survey in Manila (Manila: Asian Development Bank).

Assaad, R. (1996) Formalizing the informal: the transformation of Cairo's refuse collection system. Journal of Planning Education and Research, 16, pp. 115-126.

Bakker K. (2002) From state to market? Water mercantilización in Spain. Environment and Planning A, 34(5), pp. 767-790.

Bakker K. (2003) Archipelagos and networks: urbanization and water privatization in the south. The Geographical Journal, 169(4), pp. 328-341.

Batley R., (2006) Guest editor preface: symposium on non-state provision of basic services. Public Administration and Development, 26, pp. 193-196. 
Blanc A. (2008) Small-scale Private Water Supply Service Providers in Maputo: Note on a Research Program (Maputo, Mozambique: Agence Française de Développement).

Boucher, S., Francisco, A., Rose, L., Roth, M. and Zaqueu, F. (1995) Legal Uncertainty and Land Disputes in the Periurban Areas of Mozambique: Land Markets in Transition (Madison: University of Wisconsin Press).

Boyer, A. (2006) The regulation of peri-urban areas of Maputo, Mozambique. Survey of household water resale activity in peri-urban Maputo: preliminary discussion of findings, Columbia University.

Chaponniere, E. and Collignon, B. (2011) PPP with local informal providers aimed at improving water supply in the peri-urban areas of Maputo, Mozambique. Paper presented at the 35th WEDC International Conference, Loughborough, UK.

Collignon, B. and Vézina, B. (2000) Independent Water and Sanitation Providers in African Cities. Full Report of a Tencountry Study (Washington, DC: UNDP-World Bank Water and Sanitation Program).

Conan, H. (2003) Scope and Scale of Small Scale Independent Providers in Eight Asian Cities (Manila: Asian Development Bank).

Conan, H. and Paniagua, M. (2003) The Role of Small Scale Water Providers in Serving the Poor: Summary and Recommendations. Accessed at http://www.adb.org/Documents/Events/2003/3WWF/Role_of_SSIWPs.pdf.

Conselho de Regulação do Abastecimento de Água (CRA), (2007) 'Apoio ao Conselho de Regulação do Abastecimento de Água no desenvolvimento de instrumentos reguladores para a expansão do acesso e fornecimento de serviços aos consumidores de baixa renda'. Relatório Final, 2007.

Dijk, M.P. van (2008) Role of small-scale independent providers in water and sanitation. International Journal of Water, 4(3/4), pp. 275-289.

Eales, K. (2008) Partnerships for sanitation for the urban poor: is it time to shift paradigm? IRC Symposium Sanitation for the Urban Poor. Accessed at http://www.irc.nl/page/42882.

Fernandes, E. (2002) The influence of de Soto's The Mystery of Capital. Land Lines, 14, 1.

FIPAG (2009) Database for Small Scale Providers in the Cities of Maputo, Maraquene and Matola (Maputo, Mozambique: FIPAG).

Fisher, E. (2007) Occupying the margins: labour integration and social exclusion in artisanal mining in Tanzania. Development and Change, 38(4), pp. 735-760.

Franceys, R. (2008) GATS, 'privatization' and institutional development for urban water provision: future postponed. Progress in Development Studies, 8, pp. 45-58.

Gandy, M. (2004) Rethinking urban metabolism: water, space and the modern city. City, 8(3), pp. 363-379.

Graham, S. (2000) Constructing premium network spaces: reflections on infrastructure networks and contemporary urban development. International Journal of Urban Regional Research, 24(1), pp. 183-200.

Graham, S. and Marvin, S. (2001) Splintering Urbanism: Networked Infrastructures, Technological Mobilities and the Urban Condition (London: Routledge).

Guha-Khasnobis, B., Kanbur, R. and Ostrom, E. (2006) Linking the Informal and Formal Economy: Concepts and Policies (Oxford: Oxford University Press).

Hansen, K.T. and Vaa, M. (eds) (2004) Reconsidering Informality. Perspectives from Urban Africa (Spain: Grafilur Artes Gráficas).

Hydroconseil (2008) Field Note: Improving Water Services in the Peri-urban Areas of Maputo, Mozambique (Maputo: Hydroconseil).

Jenkins, P. (2000) City profile: Maputo. Cities, 17(3), pp. 207-218.

Jenkins, P. and Wilkinson, P. (2002) Assessing the growing impact of the global economy on urban development in southern African cities: case studies in Maputo and Cape Town. Cities, 19(1), pp. 33-47.

Joshi, A. and Moore, M. (2004) Institutionalised co-production: unorthodox public service delivery in challenging environments. The Journal of Development Studies, 40(4), pp. 31-49.

Kjellén, M. and McGranahan, G. (2006) Informal water vendors and the urban poor. Human Settlements Discussion Paper Series Theme: Water-3. IIED (London).

Kudva, N. (2009) The everyday and the episodic: the spatial and political impacts of urban informality. Environment and Planning A, 41, pp. 1614-1628.

Lindell, I. (2008) The multiple sites of urban governance: insights from an African city. Urban Studies, 45, pp. $1879-1901$.

Lindell, I. (2009) 'Glocal' movements: place struggles and transnational organizing by informal workers. Geografiska Annaler, 91(2), pp. 123-136.

Matsinhe, N., Juízo, D., Macheve, B. and dos Santos, C. (2008) Regulation of formal and informal water service providers in peri-urban areas of Maputo, Mozambique. Physics and Chemistry of the Earth, 33, pp. 841-849.

Njiru, C. (2004) Utility-small water enterprise partnerships: serving informal urban settlements in Africa. Water Policy, 6, pp. $443-452$.

Paasche, T. and Sidaway, J. (2010) Transecting security and space in Maputo. Environment and Planning A, 42, pp. 15551576.

Perez Güida, V. (2009) Deconstructing informality and formalization: the case of small-scale independent water providers in Greater Maputo (Mozambique), research report, UNESCO-IHE, Department of Management and Institutions.

Pitcher, M. (2006) Forgetting from above and memory from below: strategies of legitimation and struggle in post-socialist Mozambique. Africa: Journal of the International African Institute, 76(1), pp. 88-112.

Política Nacional de Águas (1995) Conselho de Ministros, Resolucao n. 7/95, de 8 Agusto. 
Plummer, J. (2002) 'Developing inclusive public-private partnerships: the role of small-scale independent providers in the delivery of water and sanitation services', presented at the 'Making Services Work for Poor People' World Development Report (WDR) 2003/04 Workshop, Eynsham Hall, Oxford, 4-5 November 2002.

Portes, A. and Schauffler, R. (1993) Competing perspectives on the Latin American informal sector. Population and Development Review, 19(1), pp. 33-60.

Rakowski, C. (1994) Convergence and divergence in the informal sector debate: a focus on Latin America, $1984-92$. World Development, 22(4), pp. 501-516.

SAL (2006) Adapting regulation to the needs of the poor, Mozambique Case Study. Phase 1: Draft Evaluation Report, SAL Consultoria em Desenvolvimento Social Ltda.

Schaub-Jones, D. (2008) Harnessing entrepreneurship in the water sector: expanding water services through independent network operators. Waterlines, 27(4), pp. 270-288.

Smith, L. (2004) The murky waters of the second wave of neoliberalism: corporatization as a service delivery model in Cape Town. Geoforum, 35, pp. 375-393.

Snell, S. (1998) Water and Sanitation Services for the Urban Poor: Small-scale Providers: Typology \& Profiles (Washington, DC: UNDP/World Bank Water and Sanitation Program).

Solo, T. (1999) Small-scale entrepreneurs in the urban water and sanitation market. Environment and Urbanization, 11(1), pp. $117-131$.

Solo, T. (2003) Independent Water Entrepreneurs in Latin America: The Other Private Sector in Water Services (Washington, DC: World Bank).

Soto, H. de (2000) The Mystery of Capital (New York: Basic Books).

Soto, H. de (2003) The Mystery of Capital: Why Capitalism Triumphs in the West and Fails Everywhere Else (New York: Basic Books).

Spiller, P. and Savedoff, W. (eds) (1999) Spilled Water: Institutional Commitment in the Provision of Water Services (Washington DC: Inter-American Development Bank).

Swyngedouw, E. (2005) Dispossessing $\mathrm{H}_{2} \mathrm{O}$ : the contested terrain of water privatization. Capitalism Nature Socialism, $16(1)$, pp. 81-98.

WHO/UNICEF (2008) The Millenium Development Goal Report (New York: United Nations).

Woodruff, C. (2001) Review of de Soto's The Mystery of Capital. Journal of Economic Literature, 39(4), pp. 1215-1223.

World Bank (2003) Water Supply and Sanitation Sector Business Strategy (Washington, DC: World Bank).

World Bank (2004) Public and Private Sector Roles in Water Supply and Sanitation Services, Operational Guidance for World Bank Group Staff (Washington, DC: World Bank).

World Bank (2009a) Cities and Challenges for Small Scale Private Service Providers in Electricity and Water Supply: Evidence from Bangladesh, Cambodia, Kenya and the Philippines (Washington, DC: World Bank).

World Bank (2009b) Gestao Delegada do Abastecimento de Agua Urbana em Mocambique: Estudo de Caso do FIPAG e CRA (Maputo: World Bank).

Zandamela, H. (2001) Lessons from Mozambique: the Maputo Water Concession Contract. Accessed at http:// www.citizen.org/documents/Lessons $\% 20$ from $\% 20$ Mozambique.pdf. 